\section{Problems of Indian laboratories}

SIR-Hair-raising news from an Indian national laboratory has recently horrified the scientific community all over the world. A young bright scientist at such a laboratory (RRL, Bhopal) of the Council of Scientific and Industrial Research (CSIR) was humiliated and harassed, and even physically assaulted to such a degree that he was eventually driven to commit suicide in the laboratory (Hindustan Times 15 December 1988).

All commotion subsides with time, and no concrete action will be taken against this state of affairs. Yet in CSIR laboratories in India, bright scientists and especially the young are so humiliated and harassed that they eventually follow one of these three courses: they suffer everything and abandon creativity forever, they escape overseas or they commit suicide.

The fundamental cause of this malady is rooted in the structure of the CSIR laboratories and lies in the autocratic power of the director. A comparison of the working conditions of faculty members in universities and national laboratories in India and in developed countries (say, Britain or the United States) would show that, while Indian research facilities are excellent - CSIR laboratories are luxurious by the yardstick of what India can afford - academic freedom is totally lacking in CSIR laboratories. Instead, the director is all-powerful, and has virtually total control of the future careers of faculty members. There are no checks and balances on the power of the director, as

there are in universities, and no forum in which professional opinions can be freely expressed.

All this leads to the total subjugation of scientists to the director, which breeds sycophancy and corruption. Benefits and prizes go to mediocre but loyal scientists, while the bright ones are tortured.

Those in authority enjoy god-like powers and can ignore all suggestions of protest. Yet the government of India periodically and ritually sets up committees to 'revamp' CSIR, with results that have only cosmetic value. The recent Abid Hussain committee (Mr Hussain himself is not a scientist) remarkably recommended that directors should have even more power, even though they say they do not need it - they have enough already! Occasionally, the dictatorial style of directors is reported in the newspapers, but more often it is suppressed. While the protests of daring honest scientists and international pressure from intellectuals may have some short-term effect, it will be a long time before a research atmosphere can be created for creative scientists in this country. A lot more sacrifice will go into the Ganges before then.

CSIR SCIENTIST

(Name and address withheld) The decision to print this letter, for obvious reasons anonymously, is not taken lightly, but in the knowledge that the circumstances it describes persist in some, but not all, of the laboratories concerned-

EDITOR, Nature

\section{Polio in Israel}

SIR-S. C. Arya (Nature 336, 708; 1988) refers to the outbreak of paralytic poliomyelitis in Israel last summer, which extended from mid-August to early October and culminated in 15 cases (3.3 per million population) over the seven weeks, the largest number of cases since 1979. Twelve patients lived in the Hadera subdistrict on the Mediterranean coastal plain, and residents of this region were vaccinated in mid-September.

The decision to vaccinate the entire national population (with trivalent oral poliovaccine) was based on the occurrence of three cases outside the Hadera region, widely separated geographically, as well as on serological data suggesting increased susceptibility of the young adult population to type- 1 poliovirus. The significance of finding polioviruses in sewage was misunderstood by the Israeli press and others (Nature 335, 659; 1988). Health officials searched for wild poliovirus in the sewage as an indicator of where the virus was prevalent, in order to anticipate where the disease might next appear. There was no suggestion of transmission of disease through sewage.
The Health Ministry's decision to vaccinate only those under age 40 was based on the epidemiology of poliomyelitis in Israel: between 1971 and 1987, only one of 170 cases of poliomyelitis was a person 40 years old. Arya is right in saying that most people aged 40 or over had never been vaccinated, but it was felt that almost everyone who had lived through the epidemics of the 1950s had been immunized by natural exposure to the virus.

The ministry's decision was vindicated after the fact: the outbreak was stopped in its tracks by the vaccination campaign. Furthermore, analysis of blood samples taken from adults from two subdistricts before vaccination showed that 145 of 146 people aged 30 years and older $(99.3$ per cent) had neutralizing antibody titres of at least 1:4 against all three poliovirus types.

Department of Epidemiology,

PAUL E. SLATER

Ministry of Health,

Jerusalem, Israel

\section{Central Virology Laboratory,}

RACHEL HANDSHER

Sheba Medical Center,

Tel Hashomer, Israel

\section{Kidney diplomacy}

SiR-Your conclusion (Nature 337, 393; 1989) that the shortfall in donor kidneys might be made good by better international cooperation calls for serious consideration. In this sphere as in many others, two European maps have been drawn, with two separate international organizations, Eurotransplant for Western Europe and Intertransplant for the COMECON countries. This division has, to our knowledge, been breached only once, when in 1984 a Moscow surgeon sent a kidney for which no recipient had been found to Britain, where it was transplanted into a 59-year-old man (The Times 28 May 1985). Surely this initiative could in the present climate of increasing cooperation be taken up and extended.

STEWART BRITTEN (Hon. Secretary)

\section{UK-USSR Medical}

Exchange Programme,

9d Stanhope Road,

London N6 5NE, UK

\section{RU 486 abortions}

SIR-Having read Peter Coles's article (Nature 335, 486; 1988), I think that I must have expressed myself badly when talking to him.

Strictly speaking, there has been no case of a malformed baby being born to a mother who has taken RU 486 during pregnancy. The case of fetal malformation reported to the French health authorities was discovered after a termination of pregnancy at 18 weeks from conception for a very severe oligoamnios, in a woman who had taken RU 486 and whose pregnancy continued. The embryological examination did not allow any conclusions to be drawn regarding the role of RU 486 .

Given the fact that, in the case of a failure of RU 486, even when associated with a prostaglandin, the pregnancy may indeed continue to develop and that the fetus is therefore exposed to a risk of malformation - as suggested by studies in the rabbit but not confirmed in the mouse and the rat - it is imperative to suggest a termination of pregnancy by another method.

It is stipulated that the woman shall be informed of these risks and should sign, before administration of RU 486, a letter of consent in which she declares that she has understood the limitations of the method and in particular the potential risk of embryotoxicity should the pregnancy be continued despite her having taken RU 486 followed by prostaglandin.

R. HENRION

Assistance Publique,

Hôpitaux de Paris,

Clinique Universitaire Port-Royal,

123 boulevard Port-Royal,

75014 Paris, France 